\title{
Driving Simulator Validation for Nighttime Construction Work Zone Devices
}

Deborah S. McAvoy, M.S., P.E., PTOE

Research Engineer

Transportation Research Group

Department of Civil and Environmental Engineering

Wayne State University

5451 Cass Avenue

302 Schaver Building

Detroit, MI 48202

Telephone: 313/577-9950, Fax: 313/577-8126

Email: mcavoyd@wayne.edu

Kerrie L. Schattler, Ph.D.

Assistant Professor

Department of Civil Engineering and Construction

BRADLEY UNIVERSITY

1501 West Bradley Avenue

Peoria, IL 61625

Telephone: 309/677-2779, Fax: 309/677-2867

Email: kschattler@bradley.edu

Tapan K. Datta, Ph.D., P.E.

Professor

Transportation Research Group

Department of Civil and Environmental Engineering

Wayne State University

5451 Cass Avenue

208 Schaver Building

Detroit, MI 48202

Telephone: 313/577-9154, Fax: 313/577-8126

Email: tdatta@ce.eng.wayne.edu

This paper is being submitted for presentation and publication at the 86th Annual Meeting of the Transportation Research Board, January 2007, Washington, D.C.

Word Count $=6,121+(5 \times 250)=7,371$

Submission Date: November 15, 2006 


\begin{abstract}
Research was conducted to ascertain the validity of a driving simulator in determining the effectiveness of temporary traffic control devices in a work zone during nighttime hours. The research was conducted through a field study and a simulator study. The field study examined speeds at six sites and the simulator study utilized 127 human subjects. Spot speeds were observed at three locations in a freeway work zone. The location of the speed studies were at the beginning of the work zone near the transition area, in the middle of the work zone, and at the end of the work zone near the downstream taper. Statistical analyses were conducted to determine whether the participants of the study performed differently in the simulator, as compared to the field. Research results established that due to the motorist's perceived risk of work zones, driving simulators may not replicate mean speeds observed in the field.
\end{abstract}




\section{INTRODUCTION AND BACKGROUND}

As work zone fatalities have been consistently increasing nationally over the past several decades, work zone safety has become a high priority issue for road agencies and the road building industry. Between 1997 and 2002, the nation experienced an increase in work zone fatalities of nearly $55 \%$ (1). In 2002, there were 117,567 work zone crashes with 52,000 injuries and 1,181 fatalities (1) in the United States.

Work zone safety can be achieved through the provision of clear and positive guidance. Traffic control devices, specifically channelizing devices, are utilized to warn motorists of potential hazards associated with travel, especially in work zones. In most work zones, numerous drums are used as channelizing devices to assist motorists in negotiating through the work zone safely at a reasonable speed while avoiding traffic crashes and protecting workers. The drums have alternating orange and white retroreflective stripes, which makes them highly visible during nighttime travel. Warning lights mounted on the drums are used to supplement the guidance function and alert the drivers' attention to the warning devices (2). As per the Michigan Manual on Uniform Traffic Control Devices (MUTCD), Type C steady burn warning lights are intended to be used to "delineate the edge of the traveled way" on detour curves, lane changes, and lane closures (2) and are currently required on all drums, in taper and tangent sections, for nighttime use in state highway projects (3).

Several studies have been conducted in the past to determine the effectiveness of steady burn warning lights in work zones. KLD Associates (4) studied the effectiveness of steady burn warning lights mounted on drums in delineating the desired traveled way. In this study, 53 participants were exposed to slides of work zones during nighttime driving conditions with steady burn warning lights on all drums, every other drum, or none of the drums. Thirty additional motorists participated in a field study where they were asked to determine the correct driver action and their preference of various traffic control devices. For the field study, motorists drove through 16 simulated work zones during nighttime hours along a closed section of roadway in Delaware. The field study included three lighting scenarios similar to the laboratory study. This study recommended the use of steady burn warning lights on alternate channelizing devices for left lane closures and did not recommend the use of steady burn warning lights for right lane closures.

Pant and Park $(5,6)$ studied the effectiveness of steady burn warning lights in tangent and curved sections of rural highways, with and without ambient lighting, four-lane divided and undivided highways under dry, rainy and foggy weather conditions in Ohio. Both studies utilized speed, lateral placement, acceleration noise and weaving as measures of effectiveness. Both studies concluded that steady burn warning lights had no impact on driver behavior with respect to the four measures of effectiveness on rural highways.

As collection of field data related to human factors becomes increasingly difficult due to safety issues associated with human participants, driving simulators emerge as an alternative method which allows for experimental control, efficiency, low cost and ease of data collection. However, the validity of driving simulators as a useful human factor research tool is an important issue to consider. Blaauw (7) stated that behavioral validity consisted of absolute validity and relative validity. Absolute validity is the statistical indifference between numerical values, whereas relative validity is the statistical indifference between the difference in the magnitude of critical driver performance variables as observed in the simulator and real-world.

In the Tornros study (8) of driver behavior in a simulated road tunnel, 20 participants drove through a tunnel six times in each direction while speed and lateral position data was 
collected. The study found that speeds in the driving simulator were higher than in the real tunnel and that the difference in speeds was statistically significant. This led the author to conclude a lack of absolute validity.

Godley et al. (9) performed a validation study of a driving simulator for use in evaluating speeding characteristics. Twenty-four motorists participated in an instrumented car experiment where a vehicle was driven through three test sites with rumble strips and three similar sites without rumble strips. Twenty drivers participated in a simulator experiment where the simulator replicated similar highway scenarios as the instrumented car experiment. The absolute speed values were found to be different between the instrumented car and simulator experiments. The simulator experiment produced larger average speed differences between the test and control sites for two of the three trials; however, the discrepancies between the simulator and the field experiments in terms of the extent and trend of mean speeds between the control and test sites were similar. In the analysis of the interactive relative validity with a canonical correlation, all sites yielded significant correlations for mean speed. This was deemed the most important measure of validity as it demonstrated that motorists will act similar in a simulator when compared to an instrumented car when comparing test and control sites.

Klee et al. (10) performed a study where thirty participants drove an instrumented vehicle along a roadway section while speed and travel time data was collected. Similarly, twenty-one of those participants performed the same task in a driving simulator. Z-tests were performed at 95 percent level of confidence to test the hypothesis that the differences between the mean speeds of the two experiments were greater than 4.8. At ten of sixteen analysis locations, the null hypothesis was accepted and at four of sixteen locations, the null hypothesis was rejected. It was found that most of the participants drove the simulator at slower speeds than the vehicle driven in the field experiment.

Research conducted by Bella (11) validated a driving simulator for analysis of speeds in work zones. Speed data was collected in the field during daylight hours. Thirty-five participants drove the simulator through a work zone while speed data was recorded. Bella found that the speeds observed in the field were not statistically different than those observed in the simulator.

\section{METHODOLOGY AND STUDY DATA}

The objective of this research was to ascertain the validity of the Wayne State University (WSU) driving simulator in determining the effectiveness of temporary traffic control devices used in work zones during nighttime driving conditions. This research is specifically aimed at evaluating the effectiveness of drums with and without steady burn warning lights. To accomplish this objective, the research included a field study and a driving simulator experiment. A comparative parallel 'control and test' study was conducted to determine the effectiveness of the steady burn warning lights using both a field study and a simulator study. The validity of the driving simulator was determined through the comparison of the field and driving simulator speed data.

\section{Field Study Sites}

The sites selected for this research included work zones along major freeways with a variety of geographic, environmental, and traffic conditions in Michigan. A 'test' site was considered a work zone where drums were being used without the steady burn warning lights, whereas a 'control' site was a location where drums with steady burn warning lights were being used.

The sites had similar lane widths and utilized a $10 \mathrm{mph}$ speed reduction in the work zone (60 mph) as compared to the pre-construction speed limit of $70 \mathrm{mph}$. Data was collected at the 
field sites during periods when no apparent construction activity was occurring. The characteristics of the sites used in the field study are shown in Table 1.

TABLE 1 Field Study Site Characteristics

\begin{tabular}{|l|c|c|c|c|c|c|c|}
\hline Category & Location & $\begin{array}{c}\text { Site } \\
\text { Type }\end{array}$ & $\begin{array}{c}\text { Urban/ } \\
\text { Rural } \\
\text { Setting }\end{array}$ & $\begin{array}{c}\text { Lighting } \\
\text { Available }\end{array}$ & $\begin{array}{c}\text { Type of } \\
\text { Lane } \\
\text { Closure }\end{array}$ & $\begin{array}{c}\text { Location } \\
\text { of } \\
\text { Drums }\end{array}$ & $\begin{array}{c}\text { Roadway } \\
\text { Volumes } \\
\text { (ADT) }\end{array}$ \\
\hline \multirow{5}{*}{ Interstate } & I-94 & Test & Urban & Mix & $\begin{array}{c}\text { WB: } \\
\text { Right } \\
\text { EB: } \\
\text { Left }\end{array}$ & $\begin{array}{c}\text { WB: } \\
\text { Right } \\
\text { EB: Left }\end{array}$ & 136,000 \\
\cline { 2 - 8 } & I-96 & Control & Urban & Ambient & $\begin{array}{c}\text { EB: } \\
\text { Right } \\
\text { WB: } \\
\text { Right }\end{array}$ & $\begin{array}{c}\text { EB: Left } \\
\text { and } \\
\text { Right } \\
\text { WB: } \\
\text { Right }\end{array}$ & 176,000 \\
\cline { 2 - 8 } & I-69 & Test & Rural & None & Shift & $\begin{array}{c}\text { Left and } \\
\text { Right }\end{array}$ & 20,950 \\
\hline \multirow{5}{*}{$\begin{array}{l}\text { Other } \\
\text { Freeway }\end{array}$} & $\begin{array}{c}\text { US-23 } \\
\text { M-43 to } \\
\text { M-89 }\end{array}$ & Control & Urban & None & Right & Right & 49,300 \\
\cline { 2 - 8 } & $\begin{array}{c}\text { US-131; } \\
\text { US-10 to } \\
\text { Luther }\end{array}$ & Test & Rural & None & Shift & $\begin{array}{c}\text { Left and } \\
\text { Right }\end{array}$ & 12,100 \\
\hline
\end{tabular}

\section{Field Data}

Speed data was collected for vehicles traveling through work zones using portable radar detectors during the nighttime driving conditions at three locations in each work zone site where a safe vantage location for speed measurements was available with less than a five degree angle of the approaching or departing vehicle. In general, the speed data was collected at the beginning of the work zone just before or immediately following the taper, in the middle of the work zone, and at the end of the work zone.

The speed data was used as an indication of the motorists' perceived risk of traveling through work zones using drums with and without steady burn warning lights. The speed data was collected and analyzed during nighttime off-peak periods when motorists were able to travel at their desired speed, unaffected by congestion experienced during the peak periods. When determining the level of service for a freeway, speeds at or near the speed limit indicates a better level of service than slower speeds. However, for the safety of motorists, as well as workers, lower speeds would indicate a safer situation where motorists have more control of their vehicle and have a greater ability to redirect their path of travel should an unexpected event occur. Therefore, for this research, slower speeds through a work zone were considered as the safer alternative.

The mean speeds, and standard deviations were calculated for the three spot speed locations (beginning, middle and end) in the field study work zones for the test and control sites. For the test sites, the number of vehicles observed ranged between 320 and 451 vehicles while 200 vehicles were observed at each location for the control sites. The mean speeds, standard deviations and sample size for each site are summarized in Table 2. 
TABLE 2 Field Study Speed Data Summary

\begin{tabular}{|c|c|c|c|c|c|}
\hline $\begin{array}{l}\text { Site } \\
\text { Type }\end{array}$ & Location & Variable & $\begin{array}{c}\text { Beginning of the } \\
\text { Work Zone }\end{array}$ & $\begin{array}{l}\text { Middle of the } \\
\text { Work Zone }\end{array}$ & $\begin{array}{l}\text { End of the } \\
\text { Work Zone }\end{array}$ \\
\hline \multirow{15}{*}{ Test } & \multirow{3}{*}{ I-94 } & Mean Speed (mph) & 61.97 & 55.06 & 65.65 \\
\hline & & Standard Deviation & 6.25 & 6.70 & 5.50 \\
\hline & & Sample Size & 200 & 200 & 200 \\
\hline & \multirow{3}{*}{ I-69 } & Mean Speed (mph) & 58.94 & $*$ & 57.57 \\
\hline & & Standard Deviation & 4.57 & $*$ & 4.09 \\
\hline & & Sample Size & 112 & $*$ & 112 \\
\hline & \multirow{3}{*}{$\begin{array}{l}\text { US-131; } \\
\text { M-43 to } \\
\text { M-89 }\end{array}$} & Mean Speed (mph) & 60.96 & 54.81 & 55.14 \\
\hline & & Standard Deviation & 5.84 & 3.41 & 4.80 \\
\hline & & Sample Size & 50 & 72 & 79 \\
\hline & \multirow{3}{*}{$\begin{array}{l}\text { US-131; } \\
\text { US-10 to } \\
\text { Luther }\end{array}$} & Mean Speed (mph) & 56.67 & 56.94 & 65.32 \\
\hline & & Standard Deviation & 4.36 & 2.89 & 5.03 \\
\hline & & Sample Size & 57 & 48 & 60 \\
\hline & \multirow{3}{*}{ Summary } & Mean Speed (mph) & 60.32 & 55.28 & 61.76 \\
\hline & & Standard Deviation & 5.86 & 5.68 & 6.73 \\
\hline & & Sample Size & 419 & 320 & 451 \\
\hline \multirow{9}{*}{ Control } & \multirow{3}{*}{ I-96 } & Mean Speed (mph) & $*$ & 58.48 & $*$ \\
\hline & & Standard Deviation & $*$ & 5.63 & $*$ \\
\hline & & Sample Size & * & 200 & * \\
\hline & \multirow{3}{*}{ US-23 } & Mean Speed (mph) & 62.82 & $*$ & 66.37 \\
\hline & & Standard Deviation & 7.20 & * & 6.61 \\
\hline & & Sample Size & 200 & * & 200 \\
\hline & \multirow{3}{*}{ Summary } & Mean Speed (mph) & 62.82 & 58.48 & 66.37 \\
\hline & & Standard Deviation & 7.20 & 5.63 & 6.61 \\
\hline & & Sample Size & 200 & 200 & 200 \\
\hline
\end{tabular}

*Location where a safe vantage point was not accessible.

\section{Simulator Study}

The driving simulator used in this research was a Doron Precision Systems, Inc. AMOSII. The simulator is operated from one control station and is networked with five individual computers that project the virtual reality scenarios on displays that produce a realistic 225-degree panoramic field of view for the driver. The simulator's display updates at a frame rate of $30 \mathrm{~Hz}$ with a resolution of $640 \times 480$. The distance from the driver's eye to the screen depends on the seat height, which allows for 28 " to 34 " to accommodate the different heights of drivers. The simulated vehicle is operated within a computer-synthesized interactive universe, displayed from the driver's point of view (12).

Nighttime work zone scenarios were developed to simulate driving through highway work zones that have drums with and without steady burn warning lights. The scenarios covered all the necessary specifications of the drums, including lumens of light emitted from the steady burn warning lights, and traditional work zone traffic control plans to assist in creating an accurate virtual driving environment. In a typical driving scenario, the driving simulator is able to replicate a normal nighttime driving environment and is also able to simulate the retroreflectivity of traffic signs and tape on the drums. In order to simulate the retroreflectivity of the drums and the light emitted from the warning lights, photographs were taken in the field to 
determine the number of drums and lights visible from an automobile and the simulated driving scenarios were designed to replicate the field conditions.

The simulated driving environments were designed to replicate the temporary traffic control conditions observed in the field. The field data for this project was collected prior to October 1, 2005, before the adoption of the 2005 Michigan MUTCD, Part 6, Temporary Traffic Control was adopted (2). Therefore, both the field experiment and the simulator experiment complied with the 1994 Michigan MUTCD, Part 6, Construction and Maintenance (Revised January 2001) (13). The simulated driving environments included a construction work zone along a tangent section of a two-lane (each way) divided highway with drums delineating a rightlane closure without the presence of construction activity. The drums for the construction zone were placed on both sides of the travel lanes for two reasons. First of all, half of the field study sites observed in the research had drums placed on both sides of the travel lane and secondly, to assure that the participant drove in the travel lane of the simulator instead of driving on the shoulder. Preliminary testing of the simulator experiment indicated that simulator drivers had a tendency to travel on the shoulder to ensure they did not interfere with the drums.

The first mile of each simulated driving scenario is a two-lane (each way) freeway scene. Seven traffic control devices were placed along the right side of the roadway at a 700 foot spacing (13) beginning with a regulatory speed limit sign of $70 \mathrm{mph}$ located at mile-point 1.0. The remaining six devices were placed in the following order: the 'Road Work Ahead' warning sign, the 'Right Lane Closed Ahead' warning sign, the 'Reduced Speed $60 \mathrm{mph}$ Ahead' regulatory sign, the right lane closed ahead symbol warning sign, the regulatory speed limit sign of $60 \mathrm{mph}$, and a lighted arrow panel for a total distance of 0.8 miles or 4200 feet. The construction zone taper begins near the lighted arrow panel at approximately mile-point 1.8 , continues for 840 feet (13) with drum spacing at 60 feet based upon the posted speed limit and ends with a full lane closure. After the end of the taper closing the right lane, the work zone continues for another two miles with drums on both sides of the traffic lane spaced at 120 feet (13). At mile point 4.0, the work zone ends, the closed lane opens, and the speed limit is resumed to $70 \mathrm{mph}$. The simulation ended at mile point 4.1 .

A detailed test procedure/sequence was developed with standard instructions for the driver simulator experiment. The participant was first orientated to the simulator and the location of the controls and then given a brief introduction and description of the general purpose of the experiment of "testing the effect of various traffic control devices on driver behavior and performance while driving through a freeway work zone. They were then instructed to drive through the three scenarios as if they were traveling to/from work or school, driving at a constant speed based upon the conditions presented. To reduce the bias associated with their experience in the driving simulator, the participants were exposed to the two test scenarios in equal proportions of time.

The first scenario familiarized the participant with the vehicle controls and computergenerated images of the simulator through a scenario consisting of a long tangent section of a roadway. The participants were asked to inform the instructor when they felt comfortable with the simulator's controls so that they could move on to the next steps. Typically, each participant drove approximately ten minutes until they determined they were comfortable with the simulator.

The participants in this study were comprised of a sample of 127 individuals from the general driver population, selected from the WSU community and residents of the metropolitan Detroit area, with experience in driving on the region's freeway system to commute to 
work/school. The 127 participants included 94 individuals (74.02 percent) representing the WSU student population, 27 individuals ( 21.3 percent) representing the WSU staff population, and six individuals (4.7 percent) recruited from colleagues in consulting firms and health care to target the underrepresented age groups of 46 to 60 and 61 to 70 years of age. The gender breakdown of the participants was 46.5 percent male and 53.5 percent female, with varied ages and education levels. In order to generalize the data and the results of the driving simulator study, comparisons were made between the participants and the population demographics in Michigan. The chi-square goodness-of-fit test was used to test the null hypothesis that the participant profiles were similar to the population in Michigan in terms of gender and age distribution. It was found that there was no significant difference in the gender distribution between the participants and the population in Michigan.

\section{Data Collection}

The purpose of using the driving simulator is to observe and quantify the participant's reactions and driving performance in work zone with the presence or absence of steady burn warning lights on the drums without informing them of the differences.

Comparisons of the mean travel speeds were made at specific locations in the simulated work zone: at the beginning of the work zone lane closure taper, half the distance into the work activity area and at the end of the lane closure. The mean speeds and standard deviations were calculated for the three locations in the work zone (beginning, middle and end) for the test and control scenarios. Although 127 individuals participated in the study, the sample size utilized in the calculations and statistical testing varies as it reflected drivers that previously crashed in the work zone where a null speed was recorded. Outliers were also identified graphically through a box plot. Based upon the box plots of the speeds at the specified locations in the simulated work zone, the speeds of five individuals were considered abnormal. Reviews were performed of the demographical data and notes taken at the time of the simulation study regarding these five participants. Three of the participants were eliminated from the simulation study due to their lack of time to devote to the study. They indicated, upon completion of the study, that they were late for appointments and were driving in excess of $90 \mathrm{mph}$ to complete the study quickly. The other two individuals were eliminated from the study due to their limited driving experience in the United States and abroad. Participants were not allowed to partake in the study unless they had a valid driver's license and had passed a driver's training course. The final sample sizes ranged between 116 to 122 participants at the three specified locations (beginning, middle and end) in the work zone.

\section{RESULTS AND STATISTICAL TESTS}

To determine the effectiveness of the steady burn warning lights on drums in construction work zones and to ascertain the validity of using WSU's driving simulator for research associated with nighttime driving in work zones, statistical tests were performed on the mean travel speeds of the field and simulator studies.

\section{Test Statistics and Validation of Assumptions}

An analysis of variance (ANOVA) test was used to determine if the mean speeds for the field study and the simulator study varied by location in the work zone. The null hypothesis states that the mean speeds of the three specified locations in the work zone are similar. The alternative hypothesis states that there are differences between the mean speeds at any of the 
locations. As with any statistical test, the ANOVA has three underlying assumptions that must be met in order for the test to be robust. The first assumption is that the observations are random and independent. For the field study, speed data was collected randomly from the sample of motorists driving through each work zone. Therefore, this data was drawn from the population and can be considered independent. The participants in the simulator study were recruited from the WSU community and the Metropolitan Detroit Area to represent the driving population. Although the data was not randomly collected, due to the representative nature of the participants the data can be considered independent. The second assumption is that the data is normally distributed. Both the field and simulator data are approximately normally distributed. The third assumption is that the variances are homogeneous. As found in previous simulator studies $(8,9,10)$, the simulator data did not absolutely replicate the field data as indicated by the lack of homogeneity in the variances. In order to address this final issue, Box (14) described the impact of violating the homogeneity assumption. If the ratio of the largest to smallest standard deviation is less than 1.73, the probability of a Type I error is not adversely impacted by unequal variances. This ratio has been calculated and has been found to be less than the 1.73 threshold, therefore; the threat to the robustness of the test has been mitigated.

In order to test the difference between the mean speeds of the field test sites with the field control sites, the simulator test scenario with the simulator control scenario and the field study with the simulator study, two-sample case statistics were utilized. For two-sample case statistics, the test statistic is based upon the difference between two sample means, $X_{1}$ and $X_{2}$. The null hypothesis states that the difference between the mean speeds of the two samples is negligible. Likewise, the alternative hypothesis states that the mean speeds of one sample are different than the mean speeds of the second sample.

Since the population variance is not known and will be estimated by the sample variance, the sampling distribution used for the statistical analysis is the t-distribution. With the $t$ distribution, there are three assumptions that must be considered. The first assumption is that the data follows the normal distribution. As described earlier, both the field and simulator data are approximately normally distributed. The second assumption is that the data has been randomly sampled from the population and this was fulfilled as has been described earlier. The third assumption is that the population variance of one group is equal to the population variance of the second group. For the field and simulator study data, the population variance is estimated by the sample variance.

To test the homogeneity of the variance, the F Max test can be utilized. The F Max test is simply the ratio of the two variances of the samples where the larger of the two variances is utilized in the numerator. The null hypothesis for this test states that the population variance of the test group equals the population variance of the control group. The alternative hypothesis states that the population variance of the test group does not equal the population of the control group. The test statistic for the F Max test is,

$\mathrm{F}=\frac{\mathrm{s}_{1}^{2}}{\mathrm{~s}_{2}^{2}}$

The critical values for the F Max test are based upon the F distribution and are determined by the number of degrees of freedom for the field study dataset and the simulator study dataset as well as a 95 percent level of confidence or alpha equal to 0.05. If the calculated $\mathrm{F}$ Max value exceeds the critical $\mathrm{F}$ value, the null hypothesis must be rejected and the assumption of 
homogeneity fails. If the calculated F Max test value is less than the critical $\mathrm{F}$ value, the null hypothesis is not rejected and the assumption of homogeneity is valid.

If the assumption of homogeneity is valid, the standard error of the difference between the means of the samples is calculated. When the assumption of homogeneity fails, as is the case with the field and simulator study datasets, the standard error of the difference is estimated with the following equation, as recommended by Cochran and Cox (15):

$\mathrm{S}_{\mathrm{X} 1-\mathrm{X} 2}=\left\{\left(\frac{\mathrm{s}_{1}^{2}}{\mathrm{n}_{1}}\right)+\left(\frac{\mathrm{s}_{2}^{2}}{\mathrm{n}_{2}}\right)\right\}^{0.5}=\left(\mathrm{s}_{\mathrm{x} 1}+\mathrm{s}_{\mathrm{x} 2}\right)^{0.5}$

Where $\mathrm{s}_{1}{ }^{2}=$ sample variance of the first sample

$\mathrm{n}_{1}=$ sample size of the first sample

$\mathrm{s}_{2}{ }^{2}=$ sample variance of the second sample

$\mathrm{n}_{2}=$ sample size of the second sample

As the sample sizes are not equal in the field study and simulator study, the degrees of freedom are estimated with the following equation, as recommended by Satterthwaite (16):

$\mathrm{df}=\frac{\left(\mathrm{s}_{\mathrm{x} 1}+\mathrm{s}_{\mathrm{x} 2}\right)^{2}}{\frac{\left(\mathrm{s}_{\mathrm{x} 1}\right)^{2}}{\mathrm{n}_{1}-1}+\frac{\left(\mathrm{s}_{\mathrm{x} 2}\right)^{2}}{\mathrm{n}_{2}-1}}$

The test statistic for the t-distribution is as follows (17):

$\mathrm{t}=\frac{\left[\left(\mathrm{X}_{1}-\mathrm{X}_{2}\right)-\left(\mu_{1}-\mu_{2}\right)\right]}{\mathrm{S}_{\mathrm{X} 1-\mathrm{X} 2}}$

Based on the null hypothesis that there is no difference in the population means, the test statistic equation is reduced to the following:

$\mathrm{t}=\frac{\left[\left(\mathrm{X}_{1}-\mathrm{X}_{2}\right)-0\right.}{\mathrm{S}_{\mathrm{X} 1-\mathrm{X} 2}}$

For a two-tailed test with an alpha equal to 0.05 , the critical value is determined based upon the degrees of freedom as previously calculated. If the calculated t-value does not exceed the critical value, the null hypothesis is not rejected. However, if the calculated t-value does exceed the critical value, the null hypothesis is rejected.

\section{Field and Simulator Study Speeds}

The trend of the mean speeds at the three locations within the work zone for both the field study and the simulator study are depicted in Figure 1. Based on this graph, the mean speeds obtained in the field study do not reflect similar trends to those obtained in the simulator study. In addition, the trend for the mean speeds between the field and simulator studies does not seem to be similar in magnitude nor direction. 


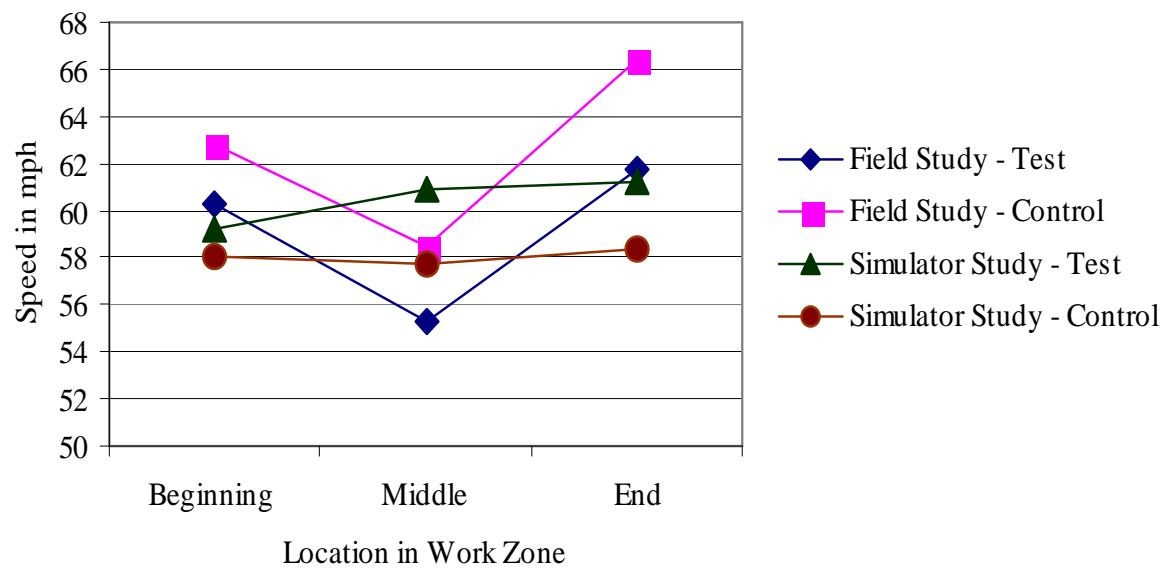

\section{FIGURE 1 Field and Simulator Mean Speed Trends.}

To determine if there were significant differences in the mean speeds in the field and simulator studies at the various locations through the work zone, an analysis of variance (ANOVA) was performed. The null hypothesis for the ANOVA stated that the mean speeds obtained at each of the locations within a work zone were similar. For example, the mean speeds obtained for the field study at the beginning, middle and end of the work zones are the same. The results from the ANOVA for the field study indicated that the mean speeds obtained at these three locations in the work zone are significantly different for both the test sites and the control sites at alpha equal to 0.05 . However, for the simulator study, it was found that the mean speeds at each of the three locations are statistically similar with the null hypothesis not being rejected at the same level of confidence. The details of the ANOVA test are shown in Table 3 and the results are summarized in Table 4.

TABLE 3 Analysis of Variance Results for the Mean Speeds through a Work Zone

\begin{tabular}{|c|c|c|c|c|c|c|}
\hline $\begin{array}{l}\text { Source of } \\
\text { Variation }\end{array}$ & $\begin{array}{c}\text { Sum of } \\
\text { Squares (SS) }\end{array}$ & $\begin{array}{c}\text { Degrees of } \\
\text { Freedom (df) }\end{array}$ & $\begin{array}{c}\text { Mean Squares } \\
\text { (MS) }\end{array}$ & F Calculated & P-Value & F Critical \\
\hline \multicolumn{7}{|c|}{ Field Study Test Sites } \\
\hline $\begin{array}{l}\text { Between } \\
\text { Groups }\end{array}$ & 8262.32 & 2 & 4131.16 & 108.87 & $3.89 * 10^{-44}$ & 3.00 \\
\hline Within Group & 45043.08 & 1187 & 37.95 & & & \\
\hline Total & 53305.4 & 1189 & & & & \\
\hline \multicolumn{7}{|c|}{ Field Study Control Sites } \\
\hline $\begin{array}{l}\text { Between } \\
\text { Groups }\end{array}$ & 6246.01 & 2 & 3123.00 & 73.66 & $2.55 * 10^{-29}$ & 3.01 \\
\hline Within Group & 25310.39 & 597 & 42.40 & & & \\
\hline Total & 31556.4 & 599 & & & & \\
\hline \multicolumn{7}{|c|}{ Simulator Study Test Scenario } \\
\hline $\begin{array}{l}\text { Between } \\
\text { Groups }\end{array}$ & 278.92 & 2 & 139.46 & 1.47 & 0.23 & 3.02 \\
\hline Within Group & 33179.3 & 349 & 95.07 & & & \\
\hline Total & 33458.22 & 351 & & & & \\
\hline \multicolumn{7}{|c|}{ Simulator Study Control Scenario } \\
\hline $\begin{array}{l}\text { Between } \\
\text { Groups }\end{array}$ & 24.21 & 2 & 12.10 & 0.10 & 0.9 & 3.02 \\
\hline Within Group & 40346.14 & 346 & 116.61 & & & \\
\hline Total & 40370.35 & 348 & & & & \\
\hline
\end{tabular}


TABLE 4 Results of Statistical Testing

\begin{tabular}{|c|c|c|c|c|c|c|}
\hline $\begin{array}{l}\text { Mean Speed } \\
\text { Variable }\end{array}$ & $\begin{array}{c}\text { Comparison } \\
\text { Mean Speed } \\
\text { Variable } \\
\end{array}$ & $\begin{array}{c}\text { Statistical } \\
\text { Test } \\
\text { Performed } \\
\end{array}$ & $\begin{array}{l}\text { Critical } \\
\text { Value }\end{array}$ & $\begin{array}{l}\text { Calculated } \\
\text { Value }\end{array}$ & df & Test Result \\
\hline \multicolumn{7}{|c|}{ Work Zone Location Mean Speed Comparisons } \\
\hline $\begin{array}{c}\text { Field Test Site; } \\
\text { Beginning, Middle } \\
\text { and End }\end{array}$ & $\begin{array}{c}\text { Field Test Site; } \\
\text { Beginning, Middle } \\
\text { and End }\end{array}$ & ANOVA & $\mathrm{F}_{\text {crit }}=3.00$ & $\mathrm{~F}_{\mathrm{calc}}=108.87$ & 1,189 & $\overline{\mathrm{X}}_{\mathrm{FTB}} \neq \stackrel{\mathrm{X}}{\mathrm{XTM}}_{\mathrm{FT}} \neq \overline{\mathrm{X}}_{\mathrm{FTE}}$ \\
\hline $\begin{array}{l}\text { Field Control Site; } \\
\text { Beginning, Middle } \\
\text { and End }\end{array}$ & $\begin{array}{c}\text { Field Control Site; } \\
\text { Beginning, Middle } \\
\text { and End }\end{array}$ & ANOVA & $\mathrm{F}_{\text {crit }}=3.01$ & $\mathrm{~F}_{\mathrm{calc}}=73.66$ & 599 & $\overline{\mathrm{X}}_{\mathrm{FCB}} \stackrel{\text { Reject null; }}{\neq \overline{\mathrm{X}}_{\mathrm{FCM}}} \neq \overline{\mathrm{X}}_{\mathrm{FCE}}$ \\
\hline $\begin{array}{l}\text { Simulator Test Site; } \\
\text { Beginning, Middle } \\
\text { and End }\end{array}$ & $\begin{array}{c}\text { Simulator Test } \\
\text { Site; Beginning, } \\
\text { Middle and End }\end{array}$ & ANOVA & $\mathrm{F}_{\text {crit }}=3.02$ & $\mathrm{~F}_{\mathrm{calc}}=1.47$ & 351 & $\overline{\mathrm{X}}_{\mathrm{STB}}=\overline{\mathrm{X}}_{\mathrm{STM}}=\overline{\mathrm{X}}_{\mathrm{STE}}$ \\
\hline $\begin{array}{l}\text { Simulator Control } \\
\text { Site; Beginning, } \\
\text { Middle and End } \\
\end{array}$ & $\begin{array}{l}\text { Simulator Control } \\
\text { Site; Beginning, } \\
\text { Middle and End } \\
\end{array}$ & ANOVA & $\mathrm{F}_{\text {crit }}=3.01$ & $\mathrm{~F}_{\mathrm{calc}}=0.10$ & 348 & $\overline{\mathrm{D}}_{\mathrm{SCB}}=\overline{\mathrm{X}}_{\mathrm{SCM}}=\overline{\mathrm{X}}_{\mathrm{SCE}}$ \\
\hline \multicolumn{7}{|c|}{ Test and Control Site Mean Speed Comparisons } \\
\hline Field Test Beginning & $\begin{array}{c}\text { Field Control } \\
\text { Beginning } \\
\end{array}$ & t-test & $\mathrm{t}_{\text {crit }}= \pm 1.96$ & $\mathrm{t}_{\mathrm{calc}}=-4.28$ & 329 & $\begin{array}{l}\text { Reject null; } \\
\overline{\mathrm{X}}_{\mathrm{FTB}} \neq \overline{\mathrm{X}}_{\mathrm{FCB}}\end{array}$ \\
\hline Field Test Middle & $\begin{array}{c}\text { Field Control } \\
\text { Middle }\end{array}$ & t-test & $\mathrm{t}_{\text {crit }}= \pm 1.96$ & $\mathrm{t}_{\mathrm{calc}}=-6.26$ & 425 & $\begin{array}{l}\text { Reject null; } \\
\overline{\mathrm{X}}_{\mathrm{FTM}} \neq \overline{\mathrm{X}}_{\mathrm{FCM}}\end{array}$ \\
\hline Field Test End & Field Control End & t-test & $\mathrm{t}_{\text {crit }}= \pm 1.96$ & $\mathrm{t}_{\mathrm{calc}}=-8.17$ & 388 & $\begin{array}{l}\text { Reject null; } \\
\overline{\mathrm{X}}_{\mathrm{FTE}} \neq \overline{\mathrm{X}}_{\mathrm{FCE}}\end{array}$ \\
\hline $\begin{array}{c}\text { Simulator Test } \\
\text { Beginning }\end{array}$ & $\begin{array}{c}\text { Simulator Control } \\
\text { Beginning } \\
\end{array}$ & t-test & $\mathrm{t}_{\text {crit }}= \pm 1.96$ & $\mathrm{t}_{\mathrm{calc}}=0.95$ & 235 & $\begin{array}{c}\text { Do not reject null; } \\
\overline{\mathrm{X}}_{\mathrm{STB}}=\overline{\mathrm{X}}_{\mathrm{SCB}}\end{array}$ \\
\hline $\begin{array}{l}\text { Simulator Test } \\
\text { Middle }\end{array}$ & $\begin{array}{c}\text { Simulator Control } \\
\text { Middle }\end{array}$ & t-test & $\mathrm{t}_{\text {crit }}= \pm 1.96$ & $\mathrm{t}_{\mathrm{calc}}=2.26$ & 228 & $\begin{array}{l}\text { Reject null; } \\
\overline{\mathrm{X}}_{\mathrm{STM}} \neq \overline{\mathrm{X}}_{\mathrm{SCM}}\end{array}$ \\
\hline Simulator Test End & $\begin{array}{l}\text { Simulator Control } \\
\text { End } \\
\end{array}$ & t-test & $\mathrm{t}_{\text {crit }}= \pm 1.96$ & $\mathrm{t}_{\mathrm{calc}}=1.98$ & 224 & $\begin{array}{l}\frac{\text { Reject null; }}{\bar{X}_{\mathrm{STE}}} \neq \overline{\mathrm{X}}_{\mathrm{SCE}} \\
\end{array}$ \\
\hline \multicolumn{7}{|c|}{ Absolute Validity Determination } \\
\hline $\begin{array}{l}\text { Simulator Test } \\
\text { Beginning }\end{array}$ & $\begin{array}{l}\text { Field Test } \\
\text { Beginning }\end{array}$ & t-test & $\mathrm{t}_{\text {crit }}= \pm 1.97$ & $\mathrm{t}_{\mathrm{calc}}=1.33$ & 150 & $\begin{array}{c}\text { Do not reject null; } \\
\overline{\mathrm{X}}_{\mathrm{STB}}=\overline{\mathrm{X}}_{\mathrm{FTB}}\end{array}$ \\
\hline $\begin{array}{c}\text { Simulator Test } \\
\text { Middle }\end{array}$ & Field Test Middle & t-test & $\mathrm{t}_{\text {crit }}= \pm 1.97$ & $\mathrm{t}_{\mathrm{calc}}=-5.71$ & 144 & $\underline{\mathrm{X}}_{\mathrm{STM}} \neq \overline{\mathrm{X}}_{\mathrm{FTM}}$ \\
\hline Simulator Test End & Field Test End & t-test & $\mathrm{t}_{\text {crit }}= \pm 1.97$ & $\mathrm{t}_{\mathrm{calc}}=0.55$ & 141 & $\begin{array}{c}\text { Do not reject null; } \\
\overline{\mathrm{X}}_{\mathrm{STE}}=\overline{\mathrm{X}}_{\mathrm{FTE}}\end{array}$ \\
\hline $\begin{array}{c}\text { Simulator Control } \\
\text { Beginning } \\
\end{array}$ & $\begin{array}{c}\text { Field Control } \\
\text { Beginning }\end{array}$ & t-test & $\mathrm{t}_{\text {crit }}= \pm 1.97$ & $\mathrm{t}_{\mathrm{calc}}=4.54$ & 195 & $\underline{\mathrm{X}}_{\mathrm{SCB}} \neq \overline{\mathrm{X}}_{\mathrm{FCB}}$ \\
\hline $\begin{array}{c}\text { Simulator Control } \\
\text { Middle }\end{array}$ & $\begin{array}{c}\text { Field Control } \\
\text { Middle }\end{array}$ & t-test & $\mathrm{t}_{\text {crit }}= \pm 1.97$ & $\mathrm{t}_{\mathrm{calc}}=0.65$ & 149 & $\begin{array}{c}\text { Do not reject null; } \\
\overline{\mathrm{X}}_{\mathrm{SCM}}=\overline{\mathrm{X}}_{\mathrm{FCM}}\end{array}$ \\
\hline $\begin{array}{l}\text { Simulator Control } \\
\text { End } \\
\end{array}$ & Field Control End & t-test & $\mathrm{t}_{\text {crit }}= \pm 1.97$ & $\mathrm{t}_{\mathrm{calc}}=7.03$ & 157 & $\begin{array}{l}\text { Reject null; } \\
\overline{\mathrm{X}}_{\mathrm{SCE}} \neq \overline{\mathrm{X}}_{\mathrm{FCE}}\end{array}$ \\
\hline \multicolumn{7}{|c|}{ Relative Validity Determination } \\
\hline $\begin{array}{c}\text { Observed Simulator } \\
\text { Test Beginning }\end{array}$ & $\begin{array}{c}\text { Expected Simulator } \\
\text { Test Beginning }\end{array}$ & Chi-Square & $\chi_{\text {crit }}^{2}=142.12$ & $\chi_{\text {calc }}^{2}=285.76$ & 118 & $\begin{array}{l}\text { Reject null; } \\
\overline{\mathrm{X}}_{\mathrm{STB}} \neq \text { Expected } \overline{\mathrm{X}}_{\mathrm{STB}}\end{array}$ \\
\hline $\begin{array}{c}\text { Observed Simulator } \\
\text { Test Middle }\end{array}$ & $\begin{array}{c}\text { Expected Simulator } \\
\text { Test Middle }\end{array}$ & Chi-Square & $\chi_{\text {crit }}^{2}=135.45$ & $\chi_{\text {calc }}^{2}=228.46$ & 110 & $\begin{array}{c}\text { Reject null; } \\
\overline{\mathrm{X}}_{\mathrm{STM}} \neq \text { Expected } \overline{\mathrm{X}}_{\mathrm{STM}}\end{array}$ \\
\hline $\begin{array}{c}\text { Observed Simulator } \\
\text { Test End }\end{array}$ & $\begin{array}{c}\text { Expected Simulator } \\
\text { Test End }\end{array}$ & Chi-Square & $\chi_{\text {crit }}^{2}=129.89$ & $\chi_{\text {calc }}^{2}=128.68$ & 105 & $\begin{array}{c}\text { Do not reject null; } \\
\overline{\mathrm{X}}_{\mathrm{STE}}=\text { Expected } \overline{\mathrm{X}}_{\mathrm{STE}}\end{array}$ \\
\hline
\end{tabular}


Statistical tests were performed to determine if the difference between the mean speeds of the field test sites and the field control sites were significant. Based upon the t-distribution test described earlier, the null hypothesis stating that the mean speeds between the field study test and control sites were similar was rejected at alpha equal to 0.05 . The results of the field t-test are summarized in Table 4. It should be noted that due to the large sample sizes, a small difference between the two mean speeds with little practical importance can be statistically significant.

Statistical tests were also performed in a similar manner for the simulator study with a null hypothesis that the mean speeds observed between the test scenario were similar to the control scenario. It was found that for the beginning of the work zone location, the null hypothesis was not rejected indicating that the mean speeds of the simulator test scenario and the simulator control scenario were statistically similar at alpha equal to 0.05 . However, for the middle and end of the work zone locations, the null hypothesis was rejected indicating that the differences in the mean speeds for the simulator test scenario and simulator control scenario were statistically significant. The results of the simulator t-test are summarized in Table 4.

\section{Simulator Validity}

In order to determine if the simulator mean speeds were similar in absolute value as well as relative value as compared to the mean speeds observed in the field study, two-sample t-tests were performed. Based upon the statistical test at an alpha of 0.05, the mean speeds of the simulator study and the field study are significantly different at the beginning, middle and end locations in the work zone for half of the tests. Therefore, the null hypothesis that the mean speeds are the same for these sites was rejected at alpha equal to 0.05. Therefore, the simulator mean speeds do not withstand the test of absolute validity. The results of the statistical tests for absolute validity are summarized in Table 4.

The relative validity of the simulator can be verified if the magnitude and direction of the mean speeds of the simulator are similar to those observed in the field. The field data shows that the observed mean speeds at the test sites were lower than those observed at the control sites by $2.5 \mathrm{mph}, 3.2 \mathrm{mph}$ and $4.61 \mathrm{mph}$ for the three work zone locations, respectively. Therefore, the simulator test scenario mean speeds should be lower than those experienced in the control sites by a similar magnitude. In order to determine the expected mean speed for the simulator test site, the percent deviation between the field control and field test sites was found for the three work zone locations, respectively, as -3.98 percent, -5.47 percent, and -1.40 percent, and was calculated using the following equation:

Percent Deviation $(\% \mathrm{D})=\left(\frac{\overline{\mathrm{X}}_{\mathrm{FC}}-\overline{\mathrm{X}}_{\mathrm{FT}}}{\overline{\mathrm{X}}_{\mathrm{FC}}}\right) * 100$

The expected speed of the simulator test scenario was then determined with the following equation:

Expected $\overline{\mathrm{X}}_{\mathrm{ST}}=\overline{\mathrm{X}}_{\mathrm{SC}}+\overline{\mathrm{X}}_{\mathrm{SC}} *(\% \mathrm{D})$

The chi-square test statistic was utilized to compare the observed simulator test mean speed with the calculated expected test mean speed for the three locations in the work zone. The results of the chi-square test indicate that there is a significant difference between the expected and the observed means speeds for the beginning and the middle work zone locations for the 
simulator test scenario at a 95 percent level of confidence. For the end work zone location, the chi-square test indicates that there is not a significant difference between the expected and observed mean speeds. Therefore, the driving simulator does not meet the relative validity tests, when compared to the field study. The results of the statistical tests for relative validity are summarized in Table 4.

\section{DISCUSSION}

With the continued roadway reconstruction efforts throughout the nation, work zone safety has been a priority for traffic engineers and road agencies. Efforts to reduce congestion during the construction period has increased the amount of construction work that occurs during the nighttime hours. Even when construction is not occurring during the nighttime hours, during the reconstruction of roadways, the work zone is maintained through the duration of the project for several months. Both construction and maintenance of a work zone, during the nighttime hours, creates additional hazards for motorists. In addition to the modified roadway conditions in work zones, visibility is reduced and drivers often experience fatigue and distraction in nighttime driving. Due to safety concerns, some highway agencies are reluctant to modify or change current practices without substantial proof that such changes will not create additional hazards for the motorists or the construction workers.

This research was designed to test the validity of a driving simulator to allow road agencies to verify the effectiveness of temporary traffic control devices for construction work zones during the nighttime hours. Mean speed has been used and proven in the past decade as an dependable variable in assessing the performance of driving simulators by several researchers including those referenced herein $(9,10,11)$. In addition, driving simulators have also been validated as a valuable research tool in human factors research. However, the findings of this research seem to indicate partial validity of the use of a driving simulator for human factors research for nighttime work zones.

As seen in the speed profiles for the field study and the simulator study, the simulator mean speeds are approximately linear, while the mean speeds from the field study indicate a drastic reduction of speed while motorists are driving through the work zone. Considering the roadway conditions along with possible driver fatigue and distraction, it can be stated that while driving through the work zone motorists believe that there are risks involved with the work zone. The retroreflectivity of the drums or lumens of the lights reflected during the nighttime driving conditions are often reduced during construction due to the dust associated with construction, road debris, or minor dents and tears in the retroreflective sheeting. The retroreflectivity of the drums in the simulator were based upon photographs taken in the field at the start of the construction season and did not simulate the deteriorating conditions of the drums throughout a season. Motorists may also be unsure if workers are present in the construction zone and, if present, will certainly reduce their speeds to avoid potential conflicts and doubled traffic fines issued by law enforcement officials frequently patrolling work zones.

Replicating the risk associated with work zones during nighttime driving conditions in a driving simulator is difficult. In a laboratory experiment, such as a driving simulator, the participant of the study does not sense any harm will be done to construction workers, their vehicle or fellow motorists. They do not expect to encounter drums that are misaligned, damaged or missing. Simulator drivers are also aware that they will not be fined for traveling at a high speed through the construction work zone. Without the participants of the study sensing the risk 
associated with driving through work zones during nighttime driving conditions, a driving simulator may not replicate the field environment entirely and thus, produce mixed results.

\section{CONCLUSIONS}

Research was conducted to determine the effectiveness of steady burn warning lights on drums in construction work zones during nighttime driving conditions through a field study and a simulator study. In addition, the results of the field study were used to validate the driving simulator as a surrogate measuring device for field data collection during the nighttime hours at or near construction work zones. The statistical analyses performed indicated that there was a significant difference in the mean speeds obtained in the field study between the test sites, those without steady burn warning lights on the drums, and the control sites, those with steady burn warning lights on the drums. The mean speeds observed in the test sites were lower than those observed in the control sites. These findings reaffirm those of Pant and Park $(5,6)$ in their research conducted in Ohio. However, the simulator study found mixed results as compared to the field study; simulator drivers did not reduce their speeds significantly while driving through the work zone. The statistical analysis of the mean speeds in the simulator study did not indicate any difference in the mean speeds observed throughout the work zone. In addition, the statistical tests for simulator validity, absolute and relative, indicated that a simulator study may not reproduce the mean travel speed of a field study for nighttime driving conditions through a work zone.

Based upon the findings of this research, it is believed that according to several past driving simulator studies, mean speeds can be used to examine the impacts of various traffic control devices, roadway configurations or pavement markings. However, when attempting to determine the impact of these measures through a work zone during nighttime driving conditions, caution should be exercised as the risk perceived by motorists during nighttime hours through work zones may not be replicated in a driving simulator.

\section{REFERENCES}

1. Work Zone Safety Fact Sheet, National Work Zone Awareness Week 2004, Federal Highway Administration.

2. Michigan Manual on Uniform Traffic Control Devices for Streets and Highways, Part 6 Temporary Traffic Control. Michigan Department of Transportation, 2005.

3. Standard Specifications for Construction, Michigan Department of Transportation, 2003.

4. Steady-Burn Warning Lights Executive Summary. KLD Associates, Inc., Huntington Station, New York, 1992.

5. Pant, P.D., and Y. Park. Effectiveness of Steady Burn Lights for Traffic Control in Tangent Sections of Highway Work Zones. Transportation Research Board, National Research Council, Washington D.C.

6. Pant, P. D., X. H. Huang, and S. A. Krishnamurthy. Steady Burn Lights in Highway Work Zones: Further Results of Study in Ohio. University of Cincinnati, Department of Civil and Environmental Engineering, Cincinnati, Ohio, 1991.

7. Blaauw, G. J. Driving Experience and Task Demands in Simulator and Instrumented Car: A Validation Study. Human Factors 24, 1982, pp. 473-486.

8. Tornros, J. Driving Behaviour in a Real and a Simulated Road Tunnel - A Validation Study. Accident Analysis and Prevention 30, 1998, pp. 497-503.

9. Godley, S. T., T. J. Triggs, B. N. Fildes. Driving Simulator Validation for Speed Research. Accident Analysis and Prevention 34, 34, April 2001, pp. 589-600. 
10. Klee, H., C. Bauer, E. Radwan, and H. Al-Deek. Preliminary Validation of Driving Simulator Based on Forward Speed. Transportation Research Record 1689, 1999, pp. 33-39.

11. Bella, Francesco. Driving Simulator Validation for Work Zone Design. Transportation Research Board Annual Meeting Compendium of Papers, Washington D.C., 2005.

12. AMOS User's Guide. Doron Precision Systems, Inc., Binghamton, New York, 2000.

13. Michigan Manual of Uniform Traffic Control Devices, 1994 Edition, Part 6, Construction and Maintenance, The Michigan State Advisory Committee on The Manual of Uniform Traffic Control Devices, The Michigan Department of Transportation and The Michigan Department of State Police, 2001.

14. Wilcox, Rand. Statistics for the Social Sciences. Academic Press, California, 1996.

15. Cochran, W.G. and G.M. Cox. Experimental Designs, John Wiley \& Sons, New York, 1957, pp. 79-80.

16. Satterthwaite, F.W. "An Approximate Distribution of Estimates of Variance Components," Biometrics Bulletin 2, 1946, pp. 110-114.

17. Hinkle, Dennis, W. Wiersma, and S. Jurs. Applied Statistics for the Behavioral Sciences, Houghton Mifflin Company, Boston, Massachusetts, 2003. 